\title{
Cerebral Hemisphere
}

National Cancer Institute

\section{Source}

National Cancer Institute. Cerebral Hemisphere. NCI Thesaurus. Code C12351.

The part of the brain that controls muscle functions and also controls speech, thought, emotions, reading, writing, and learning. The right hemisphere controls the muscles on the left side of the body, and the left hemisphere controls the muscles on the right side of the body. 